\title{
Design Idea and Model of Teaching System for Engineering Leadership
}

\author{
Wang Liguo, Wang Shujuan, Hu Dong \\ (Dept.of Electrical Engineering, Harbin Institute of Technology, Harbin 150001) \\ (No.92, Dazhi St. Dept.of Electrical Engineering Harbin Institute of Technology, Harbin 150001)
}

(wlg2001@hit.edu.cn, wsj603@hit.edu.cn, hd_hit@126.com )

Keywords: engineering leader, educational system design, scaffolding instruction mode, based-on studying projects, information platform.

\begin{abstract}
This paper studies the teaching system design and mode of specialty of HIT electrical engineering, highlighting the "research based, individualism, superior and international" engineering leadership training. We combine the theory of teaching students in accordance with their aptitude and promotion of skill development based on the project study, internship, international cooperative laboratory and innovative practical platform by the Ruth reggae's training mode. It can be the reference for constructing Gordon training model of specialty of electrical engineering of HIT.
\end{abstract}

\section{Introduction}

Since Gordon evolved the engineering leader training idea[1] in 2007, exploring a leading personal training model which has the intense sense of responsibility, the dedication to work, the ability and spirit to innovate and taking the lead in the world is a huge challenge for the education [1]. Based on this idea, how to change the thinking model, build the educational system design adapted to engineering leader training, enhance the training of engineering leader to make superior education come true are the problems need to be solved immediately for research universities.

Educational system design theory is about how to order and design the teaching activity. Reggae Luce believed that the instructional system design theory is a scientific teaching elaboration theory, which can be concluded like on goal, two processes, four links and seven tactics; Merrill first proposed a descriptive theory of knowledge [2]. The study of instructional design in China began in the mid of 1980s, emphasized the teaching theory based on constructivist learning theory and the instructional design theory. However, for the goal of leader training, how to combine the MIT Gordon similar plan and discipline-specific features, highlighting "research, personalized, superior" competitive high-quality international leader training, is still being one of the teaching links needed improvements for Research University.

Based on National Long-term Education Reform and Development Plan, electrical engineering of Harbin Institute of Technology, establish the centrality of personnel training in colleges and universities, focus on cultivating high-quality engineering leader with strong theoretical foundation and high engineering practice ability. Based on the strategic plan "to accelerate the pace of building a world-class university," my school established the "research, personalized, superior" competitive high-quality international innovative personal training goal. In reference to "Kemp Mode", "Smith Reagan Mode" and "Bergman - Moore model", starting the exploration of teaching system design theory and model based on engineering leader training. Project learning programs, student internship training, and the combination of international joint laboratories and innovative practice platforms, highlighting the big meter system centered teaching philosophy and Models.

\section{Leader training mechanism construction}

The engineering leader training models represented by MIT and Harvard University indicate that leader training is an important goal in the era of knowledge economy, and also a complicated system project. According to the features caused by industry and modularization of electrical engineering, such as high ability of engineering, deficiency of basic scientific theories and lake of deep consideration training, how to cultivate student's ability by using the knowledge of different 
courses synthetically to solve practical problems, and help the students to achieve some skills like abstracting direction of research in engineering practice and using theoretical research to guide innovational engineering are extremely important.

According to the spirit of Ministry of education about A Number of Opinions About Strengthening Research Universities Constructing The Capability of Enhancing Independent Innovation For Institution of Higher Learning, There is an imminence requirement to guide the students to be like "studying during doing" and "doing while studying", and develop the students' ability of engineering practice and lead. Hence, establishing leader training system model and new idea, advocating the new research method of teaching, and conducting leader teaching system design for the students whose major in electrical engineering are big problems needed to be solved immediately, faced by the school of electrical engineering.

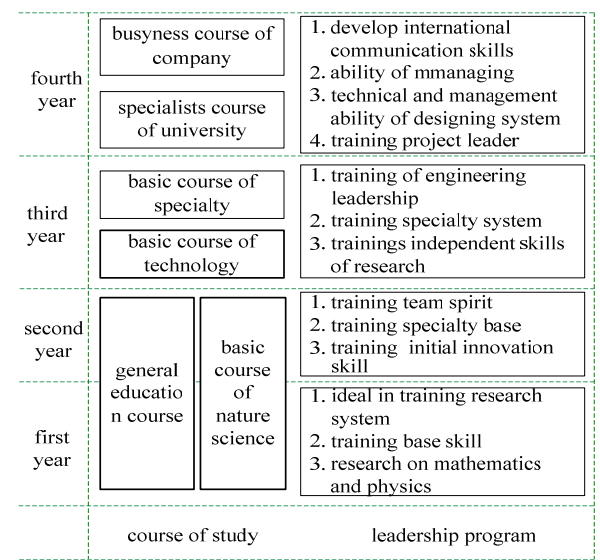

Fig.1 Courses and leader training system

Fig. 1 shows the leader training model with the characteristics of the school of electrical engineering, which reference the elite training models of Harvard University, MIT, the Chinese University of Hong Kong, National Taiwan University, Tsinghua University and many other well-known worldwide universities[3,4,5]; Which also Base on the experience training practice of talent accumulated for many years, take the advantages of own disciplines, and make the combination of individualized instruction and strengthening ability, general education and professional education, theoretical knowledge and innovative capabilities as the leading educational philosophy 'Being strict in qualifications for graduates; making every endeavor in educating students'. The main characteristic is exploring the leader training mechanism for different stages from freshmen year to senior year according to reverse the training solutions. The main contents go as follows:

1) Year one, in order to highlight the training of leader system research idea and basic research skills, the school offers "professional courses introduction" and project-based study to strengthen the understanding of students about mathematics and physics.

2) Year two, in order to highlight the training of leader team spirit, the school offers based-on project learning to combine general educational courses and natural scientific basic courses, highlight professional basic training and develop preliminary innovative skills.

3) Year three, in order to highlight the training of independent research and engineering leadership, the school offers innovative education, entrepreneur lectures and productive practice to train professional system, focusing on both technical and professional basis course.

4) Year four, in order to highlight the training of the ability of international communication, the school offers the training about engineering management to strengthen the ability to design a system, combining school professional courses and the courses of enterprise.

The courses and leader training system is shown in Fig. 1. Its core objective is to develop "research, personalized, superior" competitive high-quality international innovative talents, build engineering leader training mechanism. Promote "superior education" educational reform and 
international school. According to operate superior plan and personalized training, the qualitative of "top student, pacesetter, leader" has been achieved.

According to practice training, cultivate the pioneering and innovative spirit, team spirit, practical ability, and the engineering ability to solve practical problems of engineering leaders; enhance the awareness, quality and ability of engineering. Highlight the cultivation of ability of design, potential of a leader, international view, ambitious and realistic and creative spirit. Strengthen foreign language and practice teaching and encourage scientific innovation and scientific research participation to highlight the engineering education and characteristics. The leaders who can play an important role in technical area in the future and the superior training mechanism have high competitive internationally could be built. And explore educational system design theory and model which can make the training mechanism come true.

\section{Educational system design idea and model}

Educational model is the reflect of the educational structure in the specific subject during the educational process, is also the educational methods which are structured and organized[6]. The same educational structure can derivative several educational model to guide specific educational process in different educational contents, environments and objects. To meet the need of leader training, this paper discussed educational system design idea and model from two levels.

\section{1 educational system design idea}

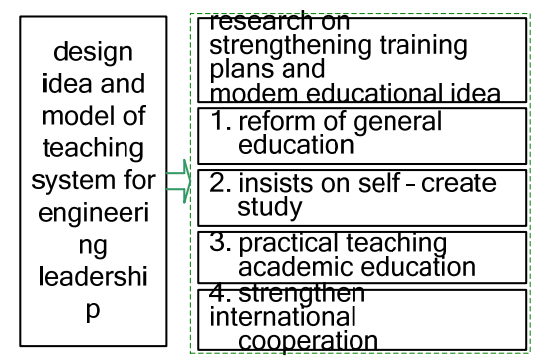

Fig.2 leader training educational system

Based on Einstein's theory "imagination is more important than knowledge"[7], educational system design and model is sophisticated, considering theory and engineering, abstracting the research theme in engineering practice, and designing the engineering system based on the theoretical knowledge.

According to Gagne’s educational system design theory "Ninth Five Matrix", the leader training educational system design must consider all the factors which have influence on the process. Highlight the idea of engineering leader training, based on the revision of training program as the carrier. As shown in the Fig. 2, the core of leader training educational system design is strengthening general education, encouraging independent innovation, enhancing the awareness of innovative practice and the ability of international communication. Based on the principle of "priority development, educating people, superior education, innovation, international standards, quality improvement" mentioned by Harbin Institute of Technology "Twelve Five" Undergraduate Education Development Plan. Inference the innovative talent training of famous universities worldwide to conduct the engineering leader training.

\subsection{Educational System Design Mode}

Professor Martin Trow pointed out that, "the development of mass higher education does not mean that we should get rid of superior education[8], on the contrary, it means that we should protect superior education. Government should fulfill the responsibility to support, protect and develop superior education.” Therefore, another key point of this paper is discussing about how to realize superior education with the satisfactory of mass higher education. With the process of systematically doing research on Herbart's four-stage education method, Kairov's six-stage education method and Babanski's “optimization” education theory, this paper describes the leadership training mode of specialty of HIT electrical engineering. It illustrated by Fig.3. 


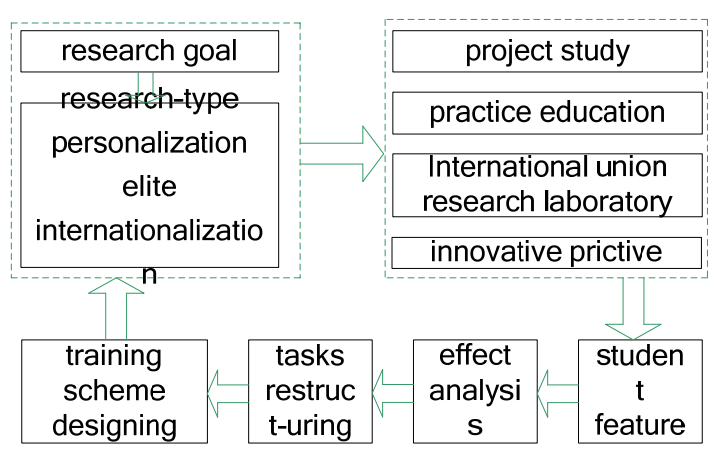

Fig.3 Training mode of electrical engineering

Fig. 3 is the training mode of specialty of HIT electrical engineering, designed according to the Reige Luth's precision processing theory, based on leadership engineering training's one system goal, concept design and weight design, and four typical design procedures. The four procedures are concluded as project study, student internship, international cooperated laboratory development and practical innovation platform. The specific content is as follows:

1) Selection. Select the training projects which can be realize from the project study, provide the platform for the leadership training.

2) Sequencing. Based on the internship, ordering the training content from general to special case, which satisfy the procedure from year one to year four in Fig 1.

3) Integration. Based on the construction of international operational laboratory, strengthen the structure and system of the training knowledge system. Realize the combination of general education and specific education.

4) Conclusion. Under the platform of selection, sequencing and integration, analyze the training efficiency according to the characteristic of students on different level. Modify the task and training strategy, establish the training system with "research based, individualism, superior and international”.

According to the needs of training talents, establish the education design mode centered with training system. Positively transform the research achievements to the content of education, use research achievements to promote education. Take the engineering case to practical use, use the research equipment as practical platform, reaching the requirements of HIT No.41 document "boost the transformation of research advantage to bachelor education". Researching on the theory and methods of informative education design based on the internet, realizing the education design of specialty of HIT electrical engineering is the most important task of this paper.

Based on the task above, two Electrical Engineering students has obtained the "best intern" in the summer internship in Eton Innovation Center in 2012, including all of the awards of "best intern". In 2013, the 7 Electrical Engineering students who are in the Eton Innovation Center training team have passed the guiding period on the digital remote education platform, and finished the final assessment of final year project.

\section{Conclusions}

In order to promote the "research based, individualism, superior and international” engineering leadership training, establish the education system design and mode of specialty of HIT electrical engineering. This paper combines the theory of teaching students in accordance with their aptitude and promotion of skill development. It also combines the general education and specialized education, theory and innovative skill training. This paper describes the training mode of specialty of electrical engineering. The special part is that it is based on the concept of project study, internship, international cooperative laboratory and innovative practical platform. It emphasizes the huge system centered education theory and mode. The research can be referenced for establishing Gordon engineering leaders plan with HIT characteristic.

\section{Reference}


[1] Lei Huan, Edward F. Crawley. Educating Engineering Leadership and Leading the World Development: The Gordon Engineering Leadership Program of MIT. Tsinghua Journal of Education.2010,31(1):77-83.

[2]Wang Zhong-hua, Xiong Mei. A Comparative Study of Yan Yuan's and James B. Conant's Educational Ideas. Forum of education culture. 2012, (6):10-14.

[3] Zhang Xiu-ping. Training of top talents with spirit of innovation and innovation of colleges\&universities education. Journal of Dalian University of Technology(Social Sciences).2005,26(1):9-15.

[4] Ye Fugui, Luo Yan. New Thinking for Cultivating Innovative Elites. Fudan Eduratinn Forum.2011,9(4):19-23.

[5] Han Xudong, Yang Tao, LiJunpeng. Exploration on the Cultivation of Outstanding Innovative Talents in the Universities with Industrial Specialty-A Case Study of Southwest Jiao tong University. Journal of South West Jiao tong University (Social Sciences). 2012,13(1):12-16.

[6] Kang Chongqing, Dong Jiajia, Dong Hong, Sun Jinsong. Preliminary Exploration of Outstanding Innovative Talents Training on Electrical Engineering Undergraduate Teaching. Research on High Education Engineering.2010, (5):132-137.

[7] Jiang Jinghua. Analysis of Cultivating Creative Talent with Particular Methods in MIT. Experimental Technology and Management.2006, 23(6):1-4.

[8] Gao Donglei, Zhou Gang, Wang Qiang. New Progress in Cultivation of Top Talents with the Spirit of Innovation in High-level Universities. Journal of Higher Education Research. 2011, 34(2):8-11. 